\title{
Advantages of using fecal samples for stable isotope analysis in bats: evidence from a triple isotopic experiment
}

\author{
loanna Salvarina ${ }^{1 *}$, Elizabeth Yohannes ${ }^{1}$, Björn M. Siemers ${ }^{2 \dagger}$ and Klemen Koselj ${ }^{2}$ \\ ${ }^{1}$ Limnological Institute, University of Konstanz, Mainaustrasse 252, D-78464 Konstanz, Gemany \\ ${ }^{2}$ Sensory Ecology Group, Max-Planck-Institute for Ornithology, D-82319 Seewiesen, Germany
}

RATIONALE: Stable isotope analysis in ecological studies is usually conducted on biomaterials, e.g. muscle and blood, that require catching the animals. Feces are rarely used for stable isotope analysis, despite the possibility of non-invasive sampling and short-term responsiveness to dietary changes. This promising method is neglected due to a lack of calibration experiments and unknown diet-feces isotopic difference $\left(\Delta_{\text {diet }}\right.$-feces $)$.

METHODS: To fill this gap, we simulated trophic changes occurring in nature when animals switch feeding habitats, e.g. by moving from freshwater to terrestrial systems, from cultivated areas to forests or changing distance from marine environments. In a controlled experiment, the diet of two bat species (Myotis myotis, Rhinolophus ferrumequinum) was altered to an isotopically distinct one. We measured stable nitrogen, carbon and the rarely used sulfur isotope in feces, and calculated $\Delta_{\text {diet feces }}$ values.

RESULTS: The feces acquired the new dietary signature within 2-3 $\mathrm{h}$ from food ingestion; thus, they are suited for detecting recent and rapid dietary changes. The $\Delta_{\text {diet feces }}(\Delta)$ did not differ between species or diet (overall means \pm standard deviation (sd)): $\Delta^{15} \mathrm{~N}: 1.47 \pm 1.51 \%, \Delta^{13} \mathrm{C}:-0.11 \pm 0.80 \%, \Delta^{34} \mathrm{~S}: 0.74 \pm 1.10 \%$. Only $\Delta^{15} \mathrm{~N}$ for $M$. myotis was significantly different from zero and only $\triangle^{13} \mathrm{C}$ differed among the days of the experiment.

CONCLUSIONS: Fecal stable isotopes can be now further applied in mammalian ecology. This includes a range of applications, such as studying changes in trophic level, resource or habitat use, on a short time-scale. Such information is gaining importance for monitoring rapidly changing ecosystems under anthropogenic influence. Copyright (c) 2013 John Wiley \& Sons, Ltd.

The stable isotopes of animal tissue reflect the local dietary input over the time that the tissue was synthesized. Different tissues integrate diet over different time scales. Blood and muscle for example, which are commonly used for stable isotope analysis in mammals, ${ }^{[1,2]}$ have turnover rates of some weeks to months. ${ }^{[3]}$ However, when research questions require measurement of rapid changes in diet or trophic level, samples with a faster tumover rate such as exhaled breath or feces are required. Collection of both breath and feces is relatively easy, cost effective and non-invasive, but so far only a single element (carbon) can be measured in breath. ${ }^{[4]}$

Feces are a good candidate for stable isotope analysis with the aim of short-term diet investigation, because (i) they contain remains of the recent diet; ${ }^{[5]}$ (ii) capturing of animals is not necessarily required as feces can be collected from below roosting sites; and (iii) stable isotopes of multiple elements can be measured in a single sample. Bat ecologists

* Correspondence to: I. Salvarina, Limnological Institute, University of Konstanz, Mainaustrasse 252, D-78464 Konstanz, Germany.

E-mail: Ioanna.Salvarina@uni-konstanz.de; isalvarina@ gmail.com

+ Deceased often use feces for visual (reviewed by Painter et al. ${ }^{[6]}$ and Vaughan ${ }^{[7]}$ ) or, less frequently, molecular ${ }^{[8]}$ identification of prey items. Stable ${ }^{[9]}$ or radioisotope ${ }^{[10]}$ in old bat guano have been used as paleoclimate records. Only a few studies have conducted stable isotope analysis on bat feces to investigate ecology, ${ }^{[11]}$ habitat use, ${ }^{[12]}$ and diet. ${ }^{[5]}$

The lack of controlled experiments limits the application of fecal stable isotopes in the ecology of small mammals. Animal isotopic ecology is still lacking experimental estimations of isotopic diet-sample differences $(\Delta),{ }^{[13]}$ i.e. the difference in the isotopic content between the diet and the sample used to estimate it (also known as fractionation factor or isotopic discrimination). A difference between diet and feces is related to biochemical pathways during digestion or varying digestibility of food components with different isotope values. ${ }^{[14]}$ Ideally, the $\Delta$ value would be calculated using the food consumed and the feces egested by the animal. However, the exact diet of the study animal in the field is often unknown or unavailable for analysis. Values of $\Delta$ can vary among different biomaterials of the same individual. ${ }^{[15]}$ Thus, to reconstruct diet from stable isotopes, use isotope mixing models, or compare results of different studies, it is essential to know the $\Delta$ value for the specific biomaterials. ${ }^{[15,16]}$ Also, for refined timescale diet investigation, the turnover rate of the isotopic signature of the biomaterial is required to assign the diet to the correct time. 
Stable isotope values of different elements provide different information. Stable carbon $\left(\delta^{13} \mathrm{C}\right)$ and nitrogen $\left(\delta^{15} \mathrm{~N}\right)$ isotope ratios, commonly used in bat studies, give information about the diet, feeding habitat and trophic level of species. ${ }^{[17]}$ They also indicate whether diet originates from agricultural areas ${ }^{[18]}$ and stable sulfur isotope $\left(\delta^{34} S\right.$ values) encodes the salinity of the feeding habitat..$^{\text {(e.g. [19]) }}$ Despite its potential, the $\delta^{34} \mathrm{~S}$ value is seldom used in mammal ecology.

Our aim was to explore the potential of feces as samples for stable isotope analysis, including $\delta^{34} S$ values. We performed a diet switch experiment with captive bats, using isotopically different diets to simulate changes that could occur in nature when an animal switches diet or feeding habitat. Since $\delta^{15} \mathrm{~N}$ values are indicative of trophic level, ${ }^{[17]}$ by changing dietary $\delta^{15} \mathrm{~N}$ values, we simulated prey items of different trophic levels. Due to differences in photosynthetic pathways, $C_{3}$ and $\mathrm{C}_{4}$ plants differ in $\delta^{13} \mathrm{C}$ values. ${ }^{[20]} \mathrm{By}$ varying dietary $\delta^{13} \mathrm{C}$ values, we modeled changes that could occur when the animal is changing feeding habitats, e.g. from those cultivated with $\mathrm{C}_{4}$ plants areas (e.g. maize) to forest or other habitats with $C_{3}$ plants (temperate regions). Aquatic and terrestrial insects differ in $\delta^{13} \mathrm{C}$ and $\delta^{15} \mathrm{~N}$ values; ${ }^{[21,22]}$ thus, by changing the bats' diet in these values, we simulated a shift from feeding on terrestrial to freshwater insects. Values of $\delta^{34} \mathrm{~S}$ are related to salinity and distance from the sea, ${ }^{[23]}$ so with a change in dietary $\delta^{34} S$ values, we simulated changes that could occur when an animal is feeding at different distances from the sea.

The objectives of the experiment were to: (i) estimate the time after which a dietary switch is reflected in feces (turnover rate), and (ii) test how accurately fecal stable isotope values represent dietary isotope values. For this purpose we calculated the diet-feces isotopic differences $\left(\Delta_{\text {diet-feces }}\right)$. To obtain an impression of how applicable our results would be across species, we tested whether the fecal stable isotope values, the turnover rates and the $\Delta_{\text {diet-feces }}$ values differed between two phylogenetically distant species: Myotis myotis (Borkhausen, 1797) (greater mouse-eared bats) and Rhinolophus ferrumequinum (Schreber, 1774) (greater horseshoe bats). We measured fecal $\delta^{13} \mathrm{C}, \delta^{15} \mathrm{~N}$ and $\delta^{34} \mathrm{~S}$ values prior to, during and after the diet switches. We expected the isotopic signature in feces to provide accurate information on recently consumed food.

\section{EXPERIMENTAL}

\section{Diet}

Young instars of mealworms (larval stages of the beetle Tenebrio molitor Linnaeus, 1758) were split into two groups. They were kept at room temperature and fed for 1 month prior to the experiment, either with commercially available tin-canned tuna (Thunfischfilets, EDEKA Zentrale AG \& Co. KG, Hamburg, Germany) or with cereals (Matzinger Vollkornflocken mit Gemüse, Nestlé Purina, PetCare Deutschland $\mathrm{GmbH}$, Euskirchen, Germany). Both were supplemented with fruits and vegetables (apples, carrots, salad). The cereal diet was expected to contain lower $\delta^{13} \mathrm{C}$, $\delta^{15} \mathrm{~N}$ and $\delta^{34} \mathrm{~S}$ values than the tuna diet. ${ }^{[24]}$ We thus refer to the tuna-fed and cereals-fed mealworms as heavy-labeled and light-labeled mealworms, respectively. Shortly before the experiment started, the mealworms were supplemented with additives containing essential nutrients, including vitamins and minerals (Nutri-Cal, Albrecht $\mathrm{GmbH}$, Aulendorf, Germany and Korvimin ZVT + Reptil, WDT eG, Garbsen, Germany).

\section{Bats}

The study was conducted on two phylogenetically distant species ${ }^{[25]}$ that occur sympatrically but differ in their trophic ecology and resource use. Myotis myotis preys on ground arthropods (mainly carabid beetles) that it detects by the rustling sounds and gleans from accessible ground surfaces. ${ }^{[26]}$ Rhinolophus ferrumequinum feeds predominantly on large flying moths and beetles (mainly Scarabaeoidea), which it detects by the wing movement that is encoded in the echoes of echolocation calls. ${ }^{[27,28]}$ Different sensory access to prey leads to differences in trophic level; the diet of M. myotis is dominated by predatory arthropods, ${ }^{[2]}$ whereas herbivorous insects dominate the diet of $R$. ferrumequinum. ${ }^{[28]}$

Eight male captive bats were used for the feeding experiment: four R. ferrumequinum (weight: $17.919 .1 \mathrm{~g}$ ) and four M. myotis (weight: $29.530 .3 \mathrm{~g}$ ) individuals that were kept at $2223{ }^{\circ} \mathrm{C}$ and in $6070 \%$ relative humidity. The $R$. ferrumequinum individuals were kept together in a flight cage (length $\times$ width $\times$ height: $2.4 \times 1.2 \times 2 \mathrm{~m}$ ), but fed in separate small cages (three in $0.3 \times 0.3 \times 0.3 \mathrm{~m}$ and one in $0.6 \times 0.45 \times 0.45 \mathrm{~m}$ ) to enable individualized feces collection. The individuals remained in the feeding cages for about $23 \mathrm{~h}$ from the feeding time, after which the feces were collected. The M. myotis individuals were kept together in a flight cage $(2.4 \times 2 \times 2 \mathrm{~m})$, but fed in separate, small woven boxes $(0.15 \times 0.15 \times 0.15 \mathrm{~m}$ to $0.4 \times 0.25 \times 0.2 \mathrm{~m})$, where they remained for about $23 \mathrm{~h}$ from the feeding time until the feces were collected. Each species was fed at the beginning of the dark phase of the daily photoperiodic cycle.

\section{Protocol}

The diet was controlled and feces were collected daily for 12 days. Each $M$. myotis individual was offered $78 \mathrm{~g}$ mealworms per day and each $R$. ferrumequinum individual $56 \mathrm{~g}$, but they usually consumed less. Water was provided ad libitum to all bats. On days 1 and 2 of the experiment, bats were fed their usual diet of light-labeled mealworms. On day 3 we switched their diet to the heavy-labeled mealworms, and they were fed this diet for 7 consecutive days. On day 10 we switched their diet back to the starting diet of lightlabeled mealworms. The bats remained on this diet until the end of the experiment (days 10 to 12 ).

\section{Fecal samples}

The fecal samples were left in open Eppendorf tubes to dry at room temperature before being stored in a freezer $\left(30^{\circ} \mathrm{C}\right)$ until the analysis. The samples from one specimen of each species were excluded from the analyses, because these two bats showed an aversion to heavy-labeled mealworms, and they produced negligible amounts of feces on the days when they were fed with these mealworms. At least one fecal sample was analyzed per day, per individual bat. Thus, stable isotope analysis was conducted on a total of 72 fecal pellets. 


\section{Stable isotope analysis}

Lipids tend to be more depleted in ${ }^{13} \mathrm{C}$ than tissues. ${ }^{[29]}$ Mealworms have a high lipid content, ${ }^{[30]}$ which could lead to a bias in the results if the signature of the lipids rather than the rest of the organism is measured. To avoid this bias, we removed lipids from both types of mealworms by rinsing them twice with a 2:1 chloroform/methanol solution. Because we had had no information about the lipid content of feces, we had tested, in a pilot study, if a lipid extraction would be necessary. We used fecal samples (homogenized sub-samples from about 10 feces each) from $M$. myotis and $M$. daubentonii. Lipids were extracted with a 2:1 chloroform/methanol solution from three samples per species and both these and three untreated fecal samples were analyzed for $\delta^{13} \mathrm{C}$ values. There was no significant difference in the $\delta^{13} \mathrm{C}$ values of samples after lipid extraction and untreated samples (Mann Whitney test, $p=0.75$, own unpublished data). Based on this evidence, we proceeded without extracting lipids from the fecal samples in the current experiment. Dried and powdered sub-samples of approximately $1.5 \mathrm{mg}$ mealworms (homogenized sample from 34 mealworms) and $1.3 \mathrm{mg}$ feces were weighed in small tin cups to the nearest 0.001 $\mathrm{mg}$, using a micro-analytical balance. The samples were then combusted in a vario Micro cube elemental analyzer (Elementar, Analysensysteme $\mathrm{GmbH}$, Hanau, Germany) at the Limnological Institute, University of Konstanz, Germany. The resulting $\mathrm{CO}_{2}, \mathrm{~N}_{2}$ and $\mathrm{SO}_{2}$ were separated by gas chromatography and inserted into a Micromass Isoprime isotope ratio mass spectrometer (Isoprime Ltd, Cheadle Hulme, UK), for determination of the ${ }^{13} \mathrm{C} /{ }^{12} \mathrm{C},{ }^{15} \mathrm{~N} /{ }^{14} \mathrm{~N}$ and ${ }^{34} \mathrm{~S} /{ }^{32} \mathrm{~S}$ ratios. Measurements are reported in $\delta$-notation $\left(\delta^{13} \mathrm{C}, \delta^{15} \mathrm{~N}, \delta^{34} \mathrm{~S}\right.$ values) in parts per thousand deviations $(\%)$, where $\delta=1000 \times\left(\mathrm{R}_{\text {sample }} / \mathrm{R}_{\text {standard }}\right) \quad 1 \%$ relative to the following standards: Pee Dee Belemnite (PDB) for carbon, atmospheric $\mathrm{N}_{2}$ for nitrogen and sulfanilamide calibrated and traceable to NBS-127 (barium sulfate, $\delta^{34} \mathrm{~S}=+20.3 \%$ ) for sulfur. The ratio (R) of heavy/light isotopes is calculated as: ${ }^{13} \mathrm{C} /{ }^{12} \mathrm{C},{ }^{15} \mathrm{~N} /{ }^{14} \mathrm{~N}$ and ${ }^{34} \mathrm{~S} /{ }^{32} \mathrm{~S}$. Two sulfanilamide (Isoprime internal standards) and two casein samples were used as a laboratory standard for every eight unknowns in sequence. Data obtained with internal laboratory standards indicated measurement errors (standard deviation (SD)) of $\pm 0.05 \%, 0.15 \%$ and $0.05 \%$ for $\delta^{13} \mathrm{C}, \delta^{15} \mathrm{~N}$ and $\delta^{34} \mathrm{~S}$ values, respectively.

\section{Calculation of diet-feces isotopic differences $\left(\boldsymbol{\Delta}_{\text {diet-feces }}\right)$}

The diet-feces isotopic difference, $\Delta_{\text {diet-feces }}$ or $\Delta$, was calculated for each element as:

$$
\Delta \mathrm{X}=\delta \mathrm{X}_{\text {feces }} \delta \mathrm{X}_{\text {diet }},
$$

where $\mathrm{X}$ is: ${ }^{13} \mathrm{C},{ }^{15} \mathrm{~N}$ or ${ }^{34} \mathrm{~S}$.

We calculated the $\Delta_{\text {diet-feces }}$ values for each feces separately, by subtracting the mean $\delta \mathrm{X}$ value for the corresponding diet (heavy or light-labeled mealworms) from the feces stable isotope value. To calculate the mean values for light-labeled diet for $R$. ferrumequinum, we excluded one feces produced on the first day after the switch back to the light-labeled diet, because it appeared to still have the heavy-labeled signature and we wanted to ensure that the calculation of the $\Delta$ value corresponded to each diet separately.

\section{Statistical analyses}

As the data did not originate from a normal distribution, we used only non-parametric tests. We compared the isotopic signature of light- to the heavy-labeled mealworms with the Mann Whitney U test (five mealworm samples per group). To avoid pseudoreplication and ensure a balanced design, stable isotope values of one randomly selected feces per day and individual were included in the dataset for statistical analyses of fecal samples. We tested for differences between the stable isotope values of the diet and of the respective feces produced with the same diet, i.e. we tested whether $\Delta$ was statistically significant, using the Mann Whitney U test.

We were interested in how diet change is reflected in repeated samples of individual bats. To account for repeated measures while retaining a high statistical power, we used non-parametric longitudinal models for factorial experiments. ${ }^{[31,32]}$ For measurements of each isotope, we estimated a non-parametric model with both one whole plot factor (bat species) and one subplot which is the time factor (day of the experiment). The isotope ratio values of each individual on different days were treated as measurement repeats. We computed a non-parametric ANOVA-type statistic (ATS), which was developed for use with small sample sizes. ${ }^{[33]}$ In addition to testing for the significance of each factor and their interaction, we also tested the null hypothesis that isotope values on days 3 to 9 , when heavylabeled mealworms were fed, did not exceed the isotope values on the other days, when bats were fed their usual light-labeled diet. This was computed with the following time pattern vector shaped as a boxcar function (the same pattern was assumed for both species, respectively):

$$
\mathbf{t}=[1,1,2,2,2,2,2,2,2,1,1,1]
$$

Further details of this method can be found in Brunner et $a l^{[31]}$ and Noguchi et $a l^{[32,33]}$ With the same procedure, we tested for significant differences in $\Delta$ values among the days of the experiment and between species, and tested whether $\Delta$ values of the heavy-labeled diet exceeded those of the light-labeled diet. The analyses were performed using the nparLD package version $2.0^{[33]}$ on $\mathrm{R}$ version $2.15 .0 .^{[34]}$ No data points were excluded for this analysis.

\section{RESULTS}

\section{Isotopic signature of feces - Turnover rate}

As expected, heavy-labeled mealworms exceeded lightlabeled mealworms for all stable isotope values analyzed (Table 1). The $\delta^{13} \mathrm{C}, \delta^{15} \mathrm{~N}$ and $\delta^{34} \mathrm{~S}$ values were significantly different between the two types of mealworms (Mann Whitney $\mathrm{U}=15, \mathrm{n}=10, p=0.008$ ). Thus, the two mealworm types were, due to their different isotopic values, well suited as food in our diet-switch experiment. The $\mathrm{C} / \mathrm{N}$ mass ratio (mean $\pm \mathrm{SD}$ ) of the mealworms $(4.334 \pm 1.025)$ was similar to that of the feces $(4.239 \pm 0.682$ for M. myotis, and $4.609 \pm 0.367$ for $R$. ferrumequinum).

When the bats were fed with differently labeled food, they egested feces with the new isotopic signature on the same day that the diet switch was conducted, after $23 \mathrm{~h}$, when the feces were collected (Fig. 1). The content of stable isotopes 
Table 1. Stable isotope ratios $\left(\delta^{13} \mathrm{C}, \delta^{15} \mathrm{~N}\right.$ and $\delta^{34} \mathrm{~S}$ values) (mean \pm standard deviation: $\left.\mathrm{sd}\right)$ of the two types of mealworms and feces for the two bat species $\left(M\right.$. myotis, $R$. ferrumequinum) and the relevant diet-feces isotopic differences $\left(\Delta_{\text {diet-feces }}\right.$ or $\left.\Delta\right)$ per species and diet as well as their overall means from both species and diets

\begin{tabular}{|c|c|c|c|c|c|c|c|c|}
\hline \multirow[b]{2}{*}{ Species } & \multirow[b]{2}{*}{ samples } & \multicolumn{2}{|r|}{$\delta^{15} \mathrm{~N}$} & $\delta^{13} \mathrm{C}$ & $\delta^{34} \mathrm{~S}$ & $\Delta^{15} \mathrm{~N}$ & $\Delta^{13} \mathrm{C}$ & $\Delta^{34} S$ \\
\hline & & $\mathrm{n}$ & $($ mean $\pm s d)$ & $($ mean $\pm s d)$ & $($ mean $\pm s d)$ & $($ mean $\pm s d)$ & $($ mean $\pm s d)$ & $($ mean $\pm s d)$ \\
\hline \multirow[t]{3}{*}{ light-labeled } & mealworms & 5 & $+5.31 \pm 0.63$ & $24.54 \pm 0.76$ & $+3.19 \pm 0.61$ & & & \\
\hline & M. myotis & $15(3)$ & $+7.12 \pm 1.28$ & $24.71 \pm 1.19$ & $+3.98 \pm 0.89$ & $1.81 \pm 1.28$ & $0.17 \pm 1.10$ & $0.79 \pm 0.89$ \\
\hline & R. ferrumequinum & $15^{*}(3)$ & $+6.23 \pm 1.63$ & $24.54 \pm 1.12$ & $+4.16 \pm 1.54$ & $0.53 \pm 0.54$ & $0.16 \pm 0.98$ & $0.62 \pm 0.74$ \\
\hline \multirow[t]{3}{*}{ heavy-labeled } & mealworms & 5 & $+12.88 \pm 1.16$ & $20.50 \pm 0.81$ & $+13.30 \pm 1.73$ & & & \\
\hline & M. myotis & $21(3)$ & $+15.22 \pm 2.17$ & $20.75 \pm 0.75$ & $+14.00 \pm 1.45$ & $2.34 \pm 2.17$ & $0.25 \pm 0.75$ & $0.70 \pm 1.45$ \\
\hline & R. ferrumequinum & $21(3)$ & $+13.85 \pm 0.45$ & $20.41 \pm 0.39$ & $+14.11 \pm 1.11$ & $0.97 \pm 0.45$ & $0.09 \pm 0.39$ & $0.81 \pm 1.12$ \\
\hline both diets & both bat species & $71(6)$ & & & & $1.47 \pm 1.51$ & $0.11 \pm 0.80$ & $0.74 \pm 1.10$ \\
\hline
\end{tabular}

(a)

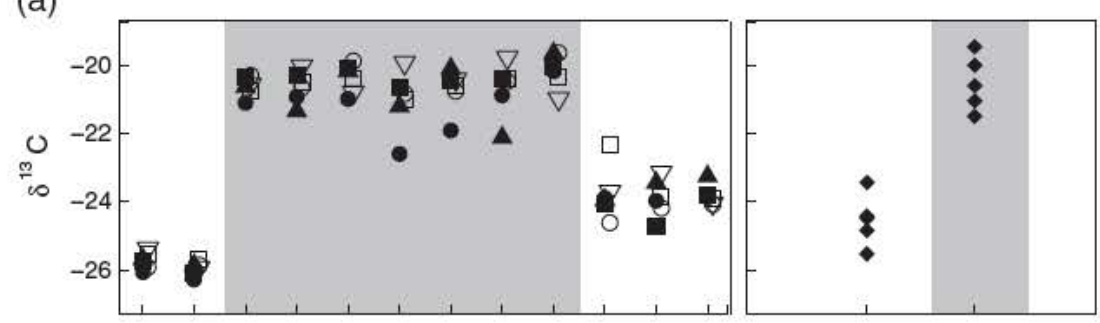

(b)

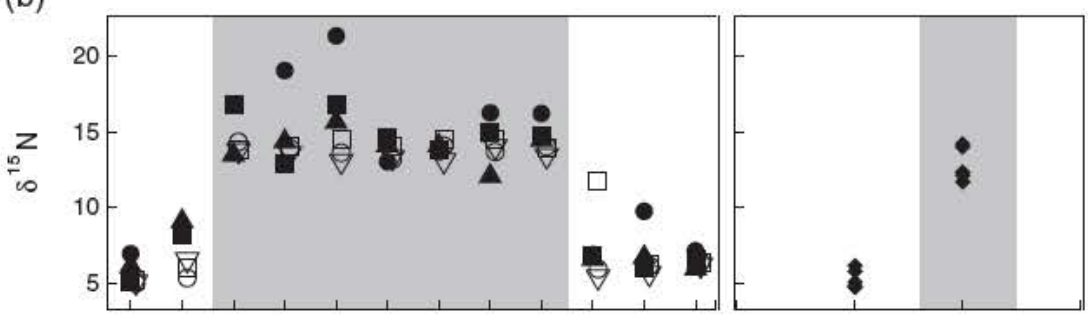

(c)

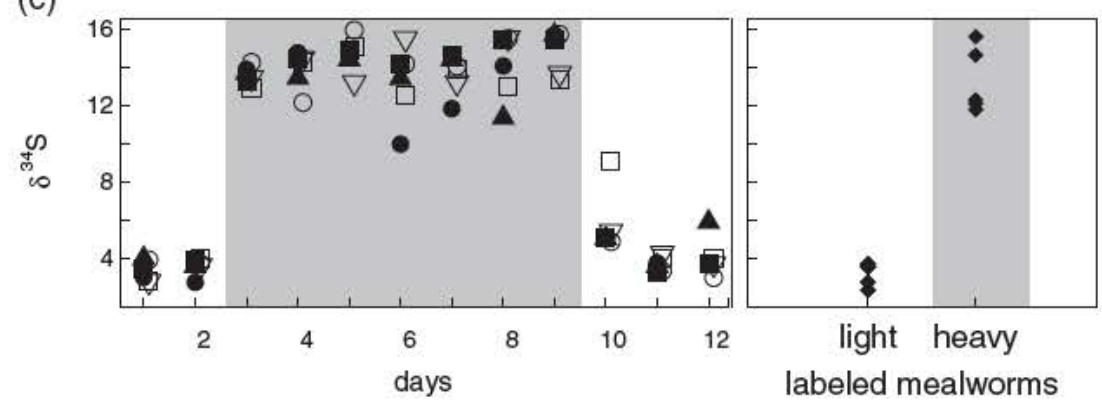
- M. myotis 1
- R. ferrumequinum 1
- M. myotis 2
$\square$ R. ferrumequinum 2
- M. myotis 3
$\nabla$ R. ferrumequinum 3

Figure 1. Fecal stable isotope ratios in each day of the experiment per species (filled symbols: $M$. myotis, open symbols: $R$. ferrumequinum), (a) $\delta^{13} \mathrm{C}$, (b) $\delta^{15} \mathrm{~N}$, (c) $\delta^{34} \mathrm{~S}$. The isotope values of light and heavy labeled mealworms (grey background) are shown in the right panels. The heavy-labeled mealworms were fed on days three to nine (grey background) and light-labeled mealworms on the remaining days. 
Table 2. Results of non-parametric longitudinal models for time, species and time-species interaction effects on the stable isotope values of $\delta^{13} \mathrm{C}, \delta^{15} \mathrm{~N}$ and $\delta^{34} \mathrm{~S}$ of the feces collected from the two bat species (M. myotis, $R$. ferrumequinum), as well as a test of higher levels of stable isotope values on days with heavy-labeled diet. These higher levels are evidenced by the statistically significant boxcar-shaped time pattern

\begin{tabular}{|llrrr|}
\hline Effect & & $\boldsymbol{\delta}^{\mathbf{1 3}} \mathrm{C}$ & $\boldsymbol{\delta}^{\mathbf{1 5}} \mathrm{N}$ & \multicolumn{1}{c|}{$\boldsymbol{\delta}^{\mathbf{3 4}} \mathrm{S}$} \\
\hline time & ATS & 26.192 & 24.179 & 20.715 \\
(ATS: ANOVA-type & df & 2.418 & 2.994 & 3.281 \\
statistic) & $p$ & $<10^{-5}$ & $<10^{-5}$ & $<10^{-5}$ \\
species (ANOVA-type & ATS & 0.948 & 5.415 & 0.039 \\
statistic with & df1 & 1.000 & 1.000 & 1.000 \\
Box modification) & df2 & 2.377 & 3.796 & 3.995 \\
& $p$ & 0.419 & 0.084 & 0.853 \\
time-species interaction & ATS & 0.911 & 0.835 & 0.707 \\
& df & 2.418 & 2.994 & 3.281 \\
boxcar-shaped time & $p$ & 0.418 & 0.474 & 0.560 \\
pattern M. myotis & ATS & 6.216 & 14.233 & 10.844 \\
& df & 2.000 & 2.000 & 2.000 \\
boxcar-shaped time & $p$ & 0.013 & 0.002 & 0.004 \\
pattern $R$. ferrumequinum & ATS & 10.446 & 13.526 & 6.847 \\
& df & 2.000 & 2.000 & 2.000 \\
& $p$ & 0.005 & 0.003 & 0.010 \\
\hline
\end{tabular}

in the feces differed among the days of the experiment, i.e. the effect of time was highly significant for all three isotopes (ANOVA-type statistic, ATS, $p<10^{-5}$; Table 2). There was no significant difference between species in any of the stable isotope values (ATS with Box modification, $p \geq 0.084$; Table 2), although a marginally non-significant difference was apparent in $\delta^{15} \mathrm{~N}$ values between species ( $p=0.084$; Table 2$)$. There was no difference between species in the manner of isotopic signature change over time, i.e. we found no statistically significant interaction between species and time ( $p \geq 0.418 ;$ Table 2). A further test revealed among which days the fecal stable isotope ratios differed; namely, the effect of time was significant, because the values of fecal stable isotopes on days with heavy-labeled diet exceeded those on the remaining days with light-labeled diet. In other words, the hypothesis of a time pattern shaped like a boxcar function could be confirmed for both species and all stable isotopes ( $p \leq 0.013$; Table 2 ). The boxcar-shaped time pattern is also visible in Fig. 1 .

\section{Diet-feces isotopic differences ( $\left.\boldsymbol{\Delta}_{\text {diet-feces }}\right)$}

The mean $\Delta_{\text {diet-feces }}$ values from all individuals (both species and both diets) were: $+1.47 \pm 1.51 \%$ o for ${ }^{15} \mathrm{~N} ; \quad 0.11 \pm 0.80 \%$ for ${ }^{13} \mathrm{C}$; and $+0.74 \pm 1.10 \%$ for ${ }^{34} \mathrm{~S}$ (Table 1). The isotopic signature did not differ between feces and diet; in other words, $\Delta$ did not differ significantly from zero in almost any case, except for ${ }^{15} \mathrm{~N}$ in feces of $M$. myotis (Table 1) which showed a statistically significant $\Delta$ for both light and heavylabeled diet (Mann Whitney $\mathrm{U}=89, p=0.015$ and $\mathrm{U}=70$, $p=0.002$, respectively). The feces of $M$. myotis had $\delta^{15} \mathrm{~N}$ values greater than those of heavy-labeled mealworms by $+2.34 \pm 2.17 \%$, and of light-labeled mealworms by $+1.81 \pm 1.28 \%$. The content of the other two stable isotopes in $M$. myotis and the content of any stable isotopes in $R$. ferrumequinum did not differ significantly between the diet and the feces (Mann Whitney U test, all $p>0.05$ and Table 1). Figure 2 shows the boxplots of the $\Delta$ values (calculated from the single $\Delta$ value of each feces) per element, per diet and per species.

The $\Delta$ values did not differ between species for any of the elements ( $p \geq 0.078$; Table 3 ). The lower $p$-value for $\Delta^{15} \mathrm{~N}$ $(0.078)$ is related to the above-mentioned significant enrichment in ${ }^{15} \mathrm{~N}$ of $M$. myotis, which was not found in $R$. ferrumequinum. Only $\Delta^{13} \mathrm{C}$ differed according to the day of the experiment, irrespective of diet $\left(p=6.9 \times 10^{-5}\right)$ (Table 3). Within the species, ${ }^{13} \mathrm{C}$ varied significantly among days in M. myotis (ATS $=6.91, \mathrm{df}=1.86, p=0.001$ ), but not in R. ferrumequinum (ATS $=2.79, \mathrm{df}=1.46, p=0.079$ ). This daily variation was not caused by the difference in the $\Delta$ values of the heavy-labeled and light-labeled diet. The $\Delta^{13} \mathrm{C}$ of heavylabeled mealworms did not exceed that of the light-labeled mealworms and the time pattern shaped like a boxcar function was not statistically significant for either of the species ( $p \geq 0.166$; Table 3 ). Rather, $\Delta^{13} \mathrm{C}$ increased slightly throughout the course of the experiment.

\section{DISCUSSION}

\section{Isotopic signature of feces}

Using a triple isotopic experiment, we showed that fecal stable isotopes rapidly reflect the most recent diet. Feces are often used in bat ecology to examine prey remains either visually or with molecular methods, in order to reveal the taxonomic identity of the prey. Stable isotopes provide information on the ecological (habitat, trophic level) and geographic origin of prey, as well as their relative contribution in the diet, when used in mixing models. ${ }^{[35]}$ Each method provides different and valuable information. These methods are complementary and should ideally be used together to give a broader picture of resource use or be selected according to the research aim.

A high $\mathrm{C} / \mathrm{N}$ mass ratio can be related to high lipid content in a particular tissue. ${ }^{[36]}$ The $\mathrm{C} / \mathrm{N}$ mass ratio of the bat feces of the feeding experiment indicates low lipid content. Lipidextracted mealworm samples had a very similar $\mathrm{C} / \mathrm{N}$ mass ratio to the feces. This confirms that lipids do not have to be extracted from the feces before the stable isotope analysis.

The bats were supplied with isotopically significantly different diets, to ensure the assignment of the feces to the respective diet. However, such large differences in dietary signatures might not always occur in the wild. In this case, multiple elements can provide more detailed information and reveal additional aspects of trophic ecology from a single sample. A three-isotope approach should be favored, as it can reveal a diet heterogeneity that could be overlooked with a dual-isotope approach. ${ }^{[37]}$ The stable sulfur isotope ratio is rarely used in animal ecology. ${ }^{\text {(but see }}{ }^{[38]}$ Our study is one of the few on mammals ${ }^{(\text {e.g. }[38])}$ adding ${ }^{34} \mathrm{~S}$ to the commonly used ${ }^{13} \mathrm{C}$ and ${ }^{15} \mathrm{~N}$ isotopes. Marine sulfur contains more of the heavy isotope and is transferred to terrestrial systems with a spray effect. ${ }^{[39]}$ Values of $\delta^{34} \mathrm{~S}$ encode the distance of feeding habitat from the sea and this makes it suited to determine food origins and to track animal movements.

The isotopic signature of the feces did not change much during the days when the bats were eating the same diet. The minor fluctuations were probably caused by the presence of varying amounts of food particles with older isotopic 

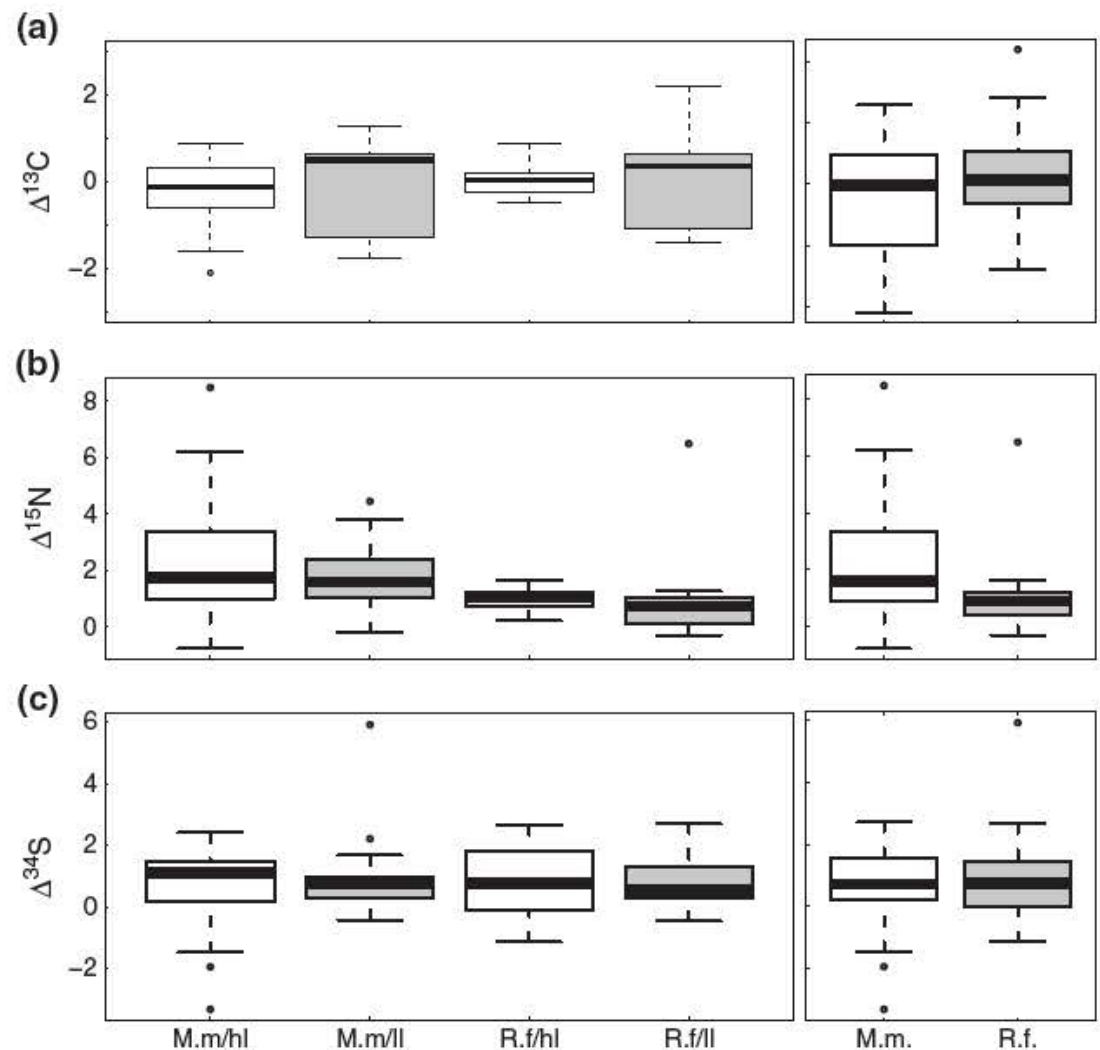

Figure 2. Diet-feces isotopic differences ( $\Delta$ diet-feces or $\Delta$ ) for stable isotopes of (a) carbon $\left(4^{13} \mathrm{C}\right),\left(\right.$ b) nitrogen $\left(\Delta^{15} \mathrm{~N}\right)$ and (c) sulfur $\left(\Delta^{34} \mathrm{~S}\right)$, for each diet (left) and pooled from both diets, light-labeled mealworms (Il) and heavy-labeled mealworms (hl), per each species, M. myotis (M.m.) and R. ferrumequinum (R.f.) (right).

Table 3. Results of non-parametric longitudinal models for time, species and time-species interaction effects on the diet-feces isotopic differences $\left(\Delta_{\text {diet-feces }}\right.$ or $\left.\Delta\right)$ of ${ }^{13} \mathrm{C}\left(\Delta^{13} \mathrm{C}\right)$, ${ }^{15} \mathrm{~N}\left(4^{15} \mathrm{~N}\right)$ and ${ }^{34} \mathrm{~S}\left(4^{34} \mathrm{~S}\right)$ of the feces collected from the two bat species (M. myotis, $R$. ferrumequinum) during the feeding experiment. Here we tested the boxcar-shaped time pattern only for ${ }^{13} \mathrm{C}$, because in other elements the $\Delta$ value did not significantly change among days (time effect was not significant). Non-significant time pattern indicates that change in $\Delta^{13} \mathrm{C}$ was not related to the diet type

\begin{tabular}{|llllll|}
\hline Effect & & $\boldsymbol{\Delta}^{\mathbf{1 3}} \mathrm{C}$ & $\boldsymbol{\Delta}^{\mathbf{1 5}} \mathbf{N}$ & $\boldsymbol{\Delta}^{\mathbf{3 4}} \mathrm{S}$ \\
\hline time (ATS: ANOVA-type & ATS & 7.777 & 1.372 & 1.766 \\
statistic) & df & 2.720 & 3.177 & 3.277 \\
& $p$ & $6.9 \times 10^{-5}$ & 0.248 & 0.146 \\
species (ANOVA-type & ATS & 0.449 & 5.571 & 0.340 \\
statistic with Box & df1 & 1.000 & 1.000 & 1.000 \\
modification) & df2 & 3.719 & 3.954 & 3.598 \\
& $p$ & 0.542 & 0.078 & 0.594 \\
time-species interaction & ATS & 1.253 & 0.816 & 0.670 \\
& df & 2.720 & 3.177 & 3.277 \\
boxcar-shaped time & $p$ & 0.289 & 0.491 & 0.583 \\
pattern $M$. myotis & ATS & 0.765 & & \\
boxcar-shaped time & df & 2.000 & & \\
pattern $R$. ferrumequinum & $p$ & 0.737 & & \\
& ATS & 1.269 & & \\
& $p$ & 2.000 & & \\
& $p$ & 0.166 & & \\
\hline
\end{tabular}

signature. There was a tendency for the $\delta^{13} \mathrm{C}$ values to increase, although the time pattern in the shape of a boxcar function was statistically significant. This could be possibly attributed to slightly increasing $\delta^{13} \mathrm{C}$ values in mealworms. The random variation in the proportion of cereals (corn and wheat) in the mixture fed to the light-labeled mealworms might have resulted in an increased $\delta^{13} \mathrm{C}$ signature. The variation in $\delta^{13} \mathrm{C}$ values of mealworms was, indeed, higher than for $\delta^{15} \mathrm{~N}$ and $\delta^{34} \mathrm{~S}$ values (Fig. 1). The increase in feces $\delta^{13} \mathrm{C}$ values might also be related to the increase of $\Delta^{13} \mathrm{C}$ throughout the experiment. Physiological processes during digestion could also explain the increase in the feces $\delta^{13} \mathrm{C}$ and $\Delta^{13} \mathrm{C}$ values during the last days of the experiment, but this would require further study.

\section{Turnover rate}

The fecal stable isotopes revealed a dietary change within $23 \mathrm{~h}$ after the new type of food had been ingested. This was evidenced by the boxcar-shaped time pattern of isotope values in feces that matched the time pattern of the isotope values of the food. Our findings complement those of another study ${ }^{[40]}$ which found comparably short gut-passage time for ingested food in M. myotis: $\left(t_{90}=77 \mathrm{~min}\right)$. The gut passage time in Eptesicus serotinus (serotine bat) ranged from $33 \mathrm{~min}$ to 32 days, decreasing with particle size ${ }^{[41]}$ We found the same turnover rate for both species considered in this study. However, this lack of interspecific difference might not be the case for the turnover rates between diet and tissues such as 
blood and skin. (for nectarivorous bats, see [42]) Therefore, when the purpose of the study is to compare diets of different species and the turnover rates of tissues from these species are unknown, feces might be a better choice to estimate diet.

\section{Diet-feces isotopic differences}

The $\Delta_{\text {diet feces }}$ that we measured can be applied to calculate dietary stable isotope values from the feces when diets are unknown or unavailable, e.g. in the field, where researchers might collect feces without catching the animals. Except for $\delta^{15} \mathrm{~N}$ values in M. myotis, we did not find any significant differences in stable isotope values between diet and feces. Stable carbon and sulfur isotopes showed no significant difference between diet and feces. The difference in $\Delta^{15} \mathrm{~N}$ between species was a non-significant trend in the longitudinal model that accounted for the repeated measures. Different proportions of digested parts of the mealworms in the feces are probably responsible for the trend of difference we found in $\triangle^{15} \mathrm{~N}$ between the two species. The relatively lower (for ${ }^{15} \mathrm{~N}$ ) and almost negligible (for ${ }^{13} \mathrm{C}$ and ${ }^{34} \mathrm{~S}$ ) $\Delta$ values, which were quite stable among the days of the experiment, species and diets, make feces a reliable source of dietary information. When reconstructing diet from fecal stable isotope values in insectivorous bats, $4^{15} \mathrm{~N}$ should be included in the calculations, while $\Delta^{13} \mathrm{C}$ and $\Delta^{34} \mathrm{~S}$ can be ignored without any loss of accuracy.

The $\Delta$ value calculated for ${ }^{13} \mathrm{C}$ between diet (mealworms) and hair of $M$. myotis ${ }^{[2]}$ was higher $(+3.58 \pm 0.28 \%$ o $)$ than we found ( $0.22 \pm 0.90 \%$ average for M. myotis from both diets). The obvious explanation is that different biochemical processes are involved in the formation of hair and digestion. The $\Delta^{15} \mathrm{~N}$ value from the previous study ${ }^{[2]}(+2.58 \pm 0.09 \%)$ is almost similar to the value we found $(+2.12 \pm 1.85 \%$ : mean \pm SD for $M$. myotis feces across diets).

The $\Delta_{\text {diet-feces }}$ that we calculated did not differ between the two species belonging to different suborders of Chiroptera. ${ }^{[25]}$ Thus, our data could be applied to other insectivorous bats or other small mammals with similar diets, bearing in mind that the $\Delta_{\text {diet-feces }}$ of species with a very different body size might differ from the ones we report. Additional factors that can affect the $\Delta$ values should be considered, e.g. food protein content, ${ }^{[43]}$ diet quality and isotopic signature, age, and condition of the organism, (for review, see ${ }^{[16]}$ or for ${ }^{15} \mathrm{~N}$, water or nutritional stress. ${ }^{\text {[4] }}$

Feces are excreted materials of an ingested diet. A disadvantage of using feces for diet investigations could be that they do not provide information on assimilated diet. However, our study indicates that feces better represent the isotopic signature of the food that was ingested than tissues do. Therefore, feces or tissue samples should be selected dependent on whether the study aims to investigate the diet, or the assimilated part of it.

\section{Further applications}

Our results can be applied to study topics such as: (i) shortterm differences of diet in bat and other mammalian species; (ii) individual or population dietary specialization; (iii) opportunistic behavior of individuals, populations or species; (iv) habitat choice; and (v) movements among different habitats. Fecal stable isotopes could be implemented to monitor pollution and investigate whether animals feed on sites with anthropogenic impact. Values of $\delta^{13} \mathrm{C}, \delta^{15} \mathrm{~N}$ and $\delta^{34} \mathrm{~S}$ differ between organic material and sewage ${ }^{[45]}$ and these values have already been used as tracers of pollution in marine systems. ${ }^{[46]}$ Bat populations in Europe and North America declined in the past century, partly due to the extensive use of pesticides in agriculture. ${ }^{[47}$ Monitoring of resource use in agricultural areas using stable isotopes might assist in developing conservation plans for bats and other small mammals.

\section{CONCLUSIONS}

We found that the $\delta^{13} \mathrm{C}, \delta^{15} \mathrm{~N}$ and $\delta^{34} \mathrm{~S}$ values in feces of insectivorous bats reflect the signature of the recently consumed diet within $23 \mathrm{~h}$ after ingestion. The turnover rate and the $\Delta$ values did not differ between two distantly related bat species fed the same diet. Thus, these results may apply to other insectivorous mammals. The $\Delta_{\text {diet-feces }}$ values from our study should be applied carefully to species with different diets. The advantages of feces are the possibility for noninvasive sampling and their suitability for answering questions concerning short-term diet or habitat variation. In combination with methods such as visual identification or molecular analysis of prey items in feces, stable isotope analysis can provide additional information and be useful for monitoring.

\section{Acknowledgements}

We thank Kamran Safi, Karl-Otto Rothhaupt and Günther Bauer for valuable comments and discussions, Wayne Dawson and Sara Troxell for the language correction of the manuscript, Renate Heckel-Merz and Birgit Beck for their assistance during the experiment and the isotopic measurements, respectively, and Kimihiro Noguchi, who kindly provided helpful advice on the use of the $R$ package nparLD. We are grateful to three anonymous reviewers whose comments improved the manuscript. Ioanna Salvarina thanks the International Max Planck Research School for Organismal Biology (IMPRS) for financial support. The study was funded by the University of Konstanz and the Max Planck Society. Bats were captured and exported under permits $35701-13 / 2003$ and $35717-20 / 2004$ of the Environmental Agency of the Republic of Slovenia and under permit Z3.48.05/AUS 0007/03 of the German Federal Agency for Nature Conservation. Bats were housed under license 301c.4V-sä of the Landratsamt Starnberg.

\section{REFERENCES}

[1] E. A. Flaherty, M. Ben David, W. P. Smith. Diet and food availability: implications for foraging and dispersal of Prince of Wales northern flying squirrels across managed landscapes. J. Mammal. 2010, 91, 79.

[2] B. M. Siemers, S. Greif, I. Borissov, S. L. Voigt Heucke, C. C. Voigt. Divergent trophic levels in two cryptic sibling bat species. Oecologia 2011, 166, 69.

[3] C. C. Voigt, F. Matt, R. Michener, T. H. Kunz. Low turnover rates of carbon isotopes in tissues of two nectar feeding bat species. J. Exp. Biol. 2003, 206, 1419. 
[4] C. C. Voigt. Studying animal diets in situ using portable stable isotope analyzers. Biotropica 2009, 41, 271.

[5] M. L. Painter, C. L. Chambers, M. Siders, R. R. Doucett, J. O. Whitaker Jr, D. L. Phillips. Diet of spotted bats (Euderma maculatum) in Arizona as indicated by fecal analysis and stable isotopes. Can. J. Zool. 2009, 87, 865.

[6] N. Vaughan. The diets of British bats (Chiroptera). Mammal Rev. 1997, 27, 77.

[7] K. Safi, G. Kerth. A comparative analysis of specialization and extinction risk in temperate zone bats. Conserv. Biol. 2004, 18, 1293

[8] K. Bohmann, A. Monadjem, C. Lehmkuhl Noer, M. Rasmussen, M. R. K. Zeale, E. Clare, G. Jones, E. Willerslev, M. T. P. Gilbert. Molecular diet analysis of two African free tailed bats (Molossidae) using high throughput sequencing. PLoS One 2011, 6, 1932.

[9] C. M. Wurster, D. A. McFarlane, M. I. Bird, P. Ascough, N. B. Athfield. Stable isotopes of subfossil bat guano as a long term environmental archive: insights from a Grand Canyon cave deposit. J. Cave Karst. Stud. 2010, $72,111$.

[10] V. E. Johnston, F. McDermott, T. Tămaş. A radiocarbon dated bat guano deposit from N.W. Romania: Implications for the timing of the Little Ice Age and Medieval Climate Anomaly. Palaeogeogr., Palaeoclimateol., Palaeoecol. 2010, $291,217$.

[11] D. J. Des Marais, J. M. Mitchell, W. G. Meinschein, J. M. Hayes. The carbon isotope biogeochemistry of the individual hydrocarbons in bat guano and the ecology of the insectivorous bats in the region of Carlsbad, New Mexico. Geochim. Cosmochim. Acta 1980, 44, 2075.

[12] J. C. Sullivan, K. J. Buscetta, R. H. Michener, J. O. Whitaker Jr, J. R. Finnerty, T. H. Kunz. Models developed from $\delta^{13} \mathrm{C}$ and $\delta^{15} \mathrm{~N}$ of skin tissue indicate non specific habitat use by the big brown bat (Eptesicus fuscus). Ecoscience 2006, 13, 11.

[13] N. Wolf, S. A. Carleton, C. Martínez del Rio. Ten years of experimental animal isotopic ecology. Funct. Ecol. 2009, $23,17$.

[14] Y. T. Hwang, J. S. Millar, F. J. Longstaffe. Do $\delta^{15} \mathrm{~N}$ and $\delta^{13} \mathrm{C}$ values of feces reflect the isotopic composition of diets in small mammals? Can. J. Zool. 2007, 85, 388.

[15] A. Borrell, N. Abad Oliva, E. Gómez Campos, J. Giménez, A. Aguilar. Discrimination of stable isotopes in fin whale tissues and application to diet assessment in cetaceans. Rapid Commun. Mass Spectrom. 2012, 26, 1596.

[16] S. Caut, E. Angulo, F. Courchamp. Variation in discrimination factors $\left(4^{15} \mathrm{~N}\right.$ and $\left.4^{13} \mathrm{C}\right)$ : the effect of diet isotopic values and applications for diet reconstruction. J. App. Ecol. 2009, 46, 443 .

[17] B. Fry. Stable Isotope Ecology. Springer, Heidelberg, 2008.

[18] C. E. Hebert, L. I. Wassenaar. Feather stable isotopes in western North American waterfowl: spatial patterns, underlying factors, and management applications. Wildife Soc. B 2005, 33, 92 .

[19] B. Fry, M. M. Chumchal. Sulfur stable isotope indicators of residency in estuarine fish. Limnol. Oceanogr. 2011, 56, 1563.

[20] J. D. Marshall, J. R. Brooks, K. Lajtha. Sources of variation in the stable isotopic composition of plants, in Stable Isotopes in Ecology and Environmental Science, (Eds: R. Michener, K. Lajtha), Blackwell Publishing, Oxford, 2007, pp. 2260 .

[21] A. Paetzold, C. J. Schubert, K. Tockner. Aquatic terrestrial linkages along a braided river: riparian arthropods feeding on aquatic insects. Ecosystems 2005, 8, 748.

[22] D. F. Raikow, D. M. Walters, K. M. Fritz, M. A. Mills. The distance that contaminated aquatic subsidies extend into lake riparian zones. Ecol. Appl. 2011, 21, 983.
[23] A. Zazzo, F. J. Monahan, A. P. Moloney, S. Green, O. Schmidt. Sulphur isotopes in animal hair track distance to sea. Rapid Commun. Mass Spectrom. 2011, 25, 2371.

[24] G. B. Nardoto, S. Silva, C. Kendall, J. R. Ehleringer, L. A. Chesson, E. S. B. Ferraz, M. Z. Moreira, J.P. H. B. Ometto, L. A. Martinelli. Geographical patterns of human diet derived from stable isotope analysis of fingernails. Am. J. Phys. Anthrop. 2006, 131, 137.

[25] E. C. Teeling, M. S. Springer, O. Madsen, P. Bates, S. J. O. O'Brien, W. J. Murphy. A molecular phylogeny for bats illuminates biogeography and the fossil record. Science $2005,307,580$.

[26] R. Arlettaz. Feeding behaviour and foraging strategy of free living mouse eared bats, Myotis myotis and Myotis blythii. Anim. Behav. 1996, 51, 1.

[27] R. Kober, H. U. Schnitzler. Information in sonar echoes of fluttering insects available for echolocating bats. J. Acoust. Soc. Am. 1990, 2, 882.

[28] G. Jones. Prey selection by the greater horseshoe bat (Rhinolophus ferrumequinum): optimal foraging by echolocation? J. Anim. Ecol. 1990, 59, 587.

[29] L. L. Tieszen, T. W. Boutton, K. G. Tesdahl, N. A. Slade. Fractionation and turnover of stable carbon isotopes in animal tissues: Implications for $\delta^{13} \mathrm{C}$ analysis of diet. Oecologia 1983, 57, 32.

[30] L. D. Jones, R. W. Cooper, R. S. Harding. Composition of mealworm Tenebrio molitor larvae. J. Zoo Anim. Med. 1972, 3,34 .

[31] E. Brunner, S. Domhof, F. Langer. Nonparametric Analysis of Longitudinal Data in Factorial Experiments. John Wiley, New York, 2002.

[32] K. Noguchi, Y. R. Gel, E. Brunner, F. Konietschke. nparLD: An $\mathrm{R}$ software package for the nonparametric analysis of longitudinal data in factorial experiments. J. Stat. Softw. $2012,50,1$.

[33] K. Noguchi, M. Latif, K. Thangavelu, F. Konietschke, Y. Gel, E. Brunner. Package nparLD: Nonparametric Analysis of Longitudinal Data in Factorial Experiments, 2012, R package version 2.0. http://CRAN.R project.org/ package $=$ nparLD .

[34] R Development Core Team. R: A language and environment for statistical computing. $\mathrm{R}$ foundation for statistical computing, 2012, Vienna, Austria. ISBN 3900051070. http://www.R project.org/.

[35] D. L. Phillips. Converting isotope values to diet composition: the use of mixing models. J. Mammal. 2012, 93, 342.

[36] D. M. Post, C. A. Layman, D. A. Arrington, G. Takimoto, J. Quattrochi, C. G. Montaña. Getting to the fat of the matter: models, methods and assumptions for dealing with lipids in stable isotope analyses. Oecologia 2007, $152,179$.

[37] R. Moreno, L. Jover, I. Munilla, A. Velando, C. Sanpera. A three isotope approach to disentangling the diet of a generalist consumer: the yellow legged gull in northwest Spain. Mar. Biol. 2010, 157, 545.

[38] P. M. Cryan, C. A. Stricker, M. B. Wunder. Evidence of cryptic individual specialization in an opportunistic insectivorous bat. J. Mammal. 2012, 93, 381.

[39] M. A. Wadleigh, H. P. Schwarcz, J. R. Kramer. Isotopic evidence for the origin of sulphate in coastal rain. Tellus $1996,48 B, 44$.

[40] J. Stalinski. Digestion, defecation and food passage rate in the insectivorous bat Myotis myotis. Acta Theriol. 1994, 39,1 .

[41] M. F. Robinson, R. E. Stebbings. Food of the serotine bat, Eptesicus serotinus is faecal analysis a valid qualitative and quantitative technique? J. Zool. 1993, 231, 239. 
[42] C. C. Voigt, F. Matt. Nitrogen stress causes unpredictable enrichments of ${ }^{15} \mathrm{~N}$ in two nectar feeding bat species. J. Exp. Biol. 2004, 207, 1741.

[43] J. H. McCutchan Jr, W. M. Lewis Jr, C. Kendall, C. C. McGrath. Variation in trophic shift for stable isotope ratios of carbon, nitrogen, and sulfur. Oikos 2003, $102,378$.

[44] J. F. Kelly. Stable isotopes of carbon and nitrogen in the study of avian and mammalian trophic ecology. Can. J. Zool. 2000, 78,1 .
[45] R. B. Spies, H. Kruger, R. Ireland, D. W. Rice Jr. Stable isotope ratios and contaminant concentrations in a sewage distorted food web. Mar. Ecol. Prog. Ser. 1989, 54, 157.

[46] C. L. Van Dover, J. F. Grassle, B. Fry, R. H. Garritt, V. R. Starczak. Stable isotope evidence for entry of sewage derived organic material into a deep sea food web. Nature 1992, 360, 153.

[47] T. H. Kunz, E. L. P. Anthony, W. T. Rumage III. Mortality of little brown bats following multiple pesticide applications. J. Wildl. Manage. 1977, 41, 476. 